\title{
Size-segregated mass distributions of aerosols over Eastern Mediterranean: seasonal variability and comparison with AERONET columnar size-distributions
}

\author{
E. Gerasopoulos $^{1,{ }^{*}}$, E. Koulouri ${ }^{1}$, N. Kalivitis ${ }^{1}$, G. Kouvarakis ${ }^{1}$, S. Saarikoski ${ }^{2}$, T. Mäkelä ${ }^{2}$, R. Hillamo ${ }^{2}$, and \\ N. Mihalopoulos ${ }^{1}$ \\ ${ }^{1}$ Environmental Chemical Processes Laboratory, Department of Chemistry, University of Crete, P.O. Box 2208, 71003 \\ Heraklion, Greece \\ ${ }^{2}$ Finnish Meteorological Institute, Air Quality Research, Erik Palmenin aukio 1, 00101, Helsinki, Finland \\ *now at: National Observatory of Athens, Institute for Environmental Research and Sustainable Development, Athens, Greece
}

Received: 6 December 2006 - Published in Atmos. Chem. Phys. Discuss.: 15 January 2007

Revised: 17 April 2007 - Accepted: 4 May 2007 - Published: 15 May 2007

\begin{abstract}
This work provides long-term (2004-2006) size segregated measurements of aerosol mass at a remote coastal station in the southern Europe, with the use of size-selective samplings (SDI impactor). Seven distinct modes were identified in the range $0-10 \mu \mathrm{m}$ and the dominant were the "Accumulation 1" $(0.25-0.55 \mu \mathrm{m})$ and the "Coarse 2" (3-7 $\mu \mathrm{m})$ modes. The seasonal characteristics of each mode were thoroughly studied and different sources for submicron and supermicron particles were identified, the first being related to local/regional and transported pollution with maximum in summer and the latter to dust from deserted areas in Northern Africa maximizing in spring. On average, $\mathrm{PM}_{2.5}$ and $\mathrm{PM}_{1}$ accounted for $60 \%$ and $40 \%$ of $\mathrm{PM}_{10}$ mass, respectively.The representativity of the ground-based measurements for the total column was also investigated by comparing the measured aerosol mass distributions with the AERONET volume size distribution data. Similar seasonal patterns were revealed and AERONET was found adequate for the estimation of background levels of both fine and coarse particles near surface, with certain limitations in the case of pollution or dust abrupt episodes due to its low temporal coverage.
\end{abstract}

\section{Introduction}

Aerosols can be introduced into the atmosphere either directly (primary aerosols) or are formed from gas phase precursors in the atmosphere (secondary aerosols). They scatter solar radiation either directly or by acting as $\mathrm{CCN}$ thus

Correspondence to: N. Mihalopoulos

(mihalo@chemistry.uoc.gr) tending to balance the warming effect by greenhouse gases (IPCC, 2001). They also uptake numerous gaseous compounds in the atmosphere and provide the appropriate surfaces for heterogeneous chemical reactions (Ravishankara, 1997) thus altering the chemical composition of the particulate phase.

The sources of aerosols as well as the processes they undergo affect their size distribution. Natural occurring particles (e.g. dust, sea salt) or aerosol products from physical mechanisms (e.g. rock grinding, sea water droplet formation) mostly produce relatively large particles. On the other hand, anthropogenic particles especially near their sources are normally fine (e.g. combustion processes, biomass burning and fossil fuel combustion).

The Mediterranean, neighboring extended deserts at the south (e.g. Sahara) and industrialized areas of Europe at the north, is one of the areas heavily affected by aerosols. Indeed $\mathrm{PM}_{10}$ measurements performed at various places both in the west and the eastern basin of the Mediterranean (e.g. Rodriguez et al., 2001; Querol et al., 2004; Andreae et al., 2002; Gerasopoulos et al., 2006) report a significant number of exceedances of the limits from the proposed legislation. Natural mechanisms such as dust transport can significantly influence (up to $80 \%$ ) the levels of measured $\mathrm{PM}_{10}$ (Andreae et al., 2002; Viana et al., 2002; Gerasopoulos et al., 2006). Under such conditions the use of $\mathrm{PM}_{10}$ for abatement strategies is highly questionable (Rodriguez et al., 2001).

This work provides two-year detailed size-segregated mass measurements at a remote site in the eastern Mediterranean. To our knowledge these are the first long-term size segregated measurements of aerosol mass in the southern Europe, a region for which a gap in terms of aerosol size

Published by Copernicus Publications on behalf of the European Geosciences Union. 
Table 1. Basic statistic quantities for the $\mathrm{PM}_{10}, \mathrm{PM}_{2.5}$ and $\mathrm{PM}_{1}$ fractions from the SDI and the Eberline Particulate Monitor. Data are given in $\mu \mathrm{g} \mathrm{m}^{-3}$. The SDI data are extracted from a number of 89 samplings.

\begin{tabular}{lcccccc}
\cline { 2 - 7 } & \multicolumn{3}{c}{ SDI } & Eberline & \multicolumn{2}{c}{ SDI } \\
\cline { 2 - 7 } & $\mathbf{P M}_{\mathbf{1 0}}$ & $\mathbf{P M}_{\mathbf{2 . 5}}$ & $\mathbf{P M}_{\mathbf{1}}$ & $\mathbf{P M}_{10}$ & $\mathbf{P M}_{\mathbf{2 . 5}} / \mathbf{P M}_{\mathbf{1 0}}$ & $\mathbf{P M}_{\mathbf{1}} / \mathbf{P M}_{\mathbf{1 0}}$ \\
\hline Max & 216.4 & 124.5 & 27.8 & 256.5 & 0.89 & 0.73 \\
3rd Quartile & 31.6 & 18.8 & 12.5 & 35.0 & 0.70 & 0.54 \\
Average & 30.8 & 18.2 & 10.1 & 33.5 & 0.63 & 0.41 \\
Median & 22.9 & 14.9 & 9.7 & 24.6 & 0.63 & 0.44 \\
1st Quartile & 17.1 & 10.2 & 6.6 & 17.3 & 0.54 & 0.28 \\
Min & 9.0 & 4.1 & 2.7 & 11.7 & 0.33 & 0.10 \\
\hline
\end{tabular}

distributions has been identified in the recent aerosol phenomenology study (Putaud et al., 2004). Size-segregated measurements could help to identify the relative contribution of natural and anthropogenic sources which in turn can be used for proposing abatement strategies. Apart from reporting the first long-term size-segregated mass measurements, this work also compares the measured aerosol mass distributions with the AERONET volume size distribution data. The aim is to conclude on the representativity of the ground based measurents for the columnar characteristics, and at the same time to provide a validation of particles size characterisation from remote sensing techniques.

\section{Data and methods}

\subsection{Sampling site}

The measurements were conducted at Finokalia $\left(35^{\circ} 20 \mathrm{~N}\right.$, $25^{\circ} 40 \mathrm{E}$ ), a remote coastal site in the northeast part of the island of Crete, Greece, in the Eastern Mediterranean. The Finokalia station is situated $70 \mathrm{~km}$ east of Heraklion, the biggest city of the island with a population of about 140000 . The major urban agglomeration of the extended area is Athens (about 4500000 inhabitants) which is located $350 \mathrm{~km}$ northwest of the station. Athens and other urban centers of the continental Europe (e.g. Istanbul) are the main sources of pollution transported over eastern Mediterranean, mainly in summer when N-NW winds prevail (Gerasopoulos et al., 2005). A description of the site and the prevailing meteorology has been previously reported by Mihalopoulos et al. (1997).

\subsection{Instrumentation and methodology of measurements}

Aerosol samples were collected using a Small-Deposit-area low-volume-Impactor (SDI; Maenhaut et al., 1996). The inlet preceding the SDI has a cut-off size of $10 \mu \mathrm{m}$. The SDI has 12 collecting stages over the particle size range 0.041$10 \mu \mathrm{m}$ with cut-offs at $0.041,0.085,0.138,0.225,0.346$, $0.585,0.762,1.06,1.66,2.68,4.08$ and $8.39 \mu \mathrm{m}$. More technical details for the operation and the set up of the SDI can be found in Teinilä et al. (2000). The average sampling time was 2 days (from 1 up to 3 days). The $\mathrm{PM}_{10}$ values were obtained by summing up the masses from all impactor stages, while the $\mathrm{PM}_{2.5}$ and $\mathrm{PM}_{1}$ values were extracted by summing up the corresponding stages. Thus, it should be kept in mind that strictly speaking the SDI actually provides $\mathrm{PM}_{2.68}$ and $\mathrm{PM}_{1.06}$. To simplify the data presentation and discussion, throughout the text we are talking about $\mathrm{PM}_{2.5}$ and $\mathrm{PM}_{1}$ for the SDI $\mathrm{PM}_{2.68}$ and $\mathrm{PM}_{1.06}$, respectively, whereas an estimate of the deviation between the above is also given in the following sections.

The $\mathrm{PM}_{10}$ mass was additionally monitored on a continuous basis with an Eberline FH 62 I-R Particulate Monitor (Eberline Instruments $\mathrm{GmbH}$ ), designed to measure the mass concentration of the suspended particles in ambient air based on $\beta$-attenuation (Gerasopoulos et al., 2006).

\subsection{AERONET volume size-distributions}

The analysis includes data from AERONET (FORTH-Crete) for the sampling period July 2004-December 2005 . In particular, quality assured (level 2.0) data were processed for volume size distributions using the retrieval procedures described previously by Dubovik and King (2000), and Dubovik et al. (2000). The retrieval errors in the particle volume size distributions, at an intermediate size range (from 0.1 to $7.0 \mu \mathrm{m}$ ), remain below $10 \%$ in the maxima of the distribution, and rise to about $35 \%$ in the minima of the distribution. The errors, however, exceed $80 \%$ for particles smaller than $0.1 \mu \mathrm{m}$ or larger than $7.0 \mu \mathrm{m}$ (Dubovik et al., 2000, 2002a). For that reason the new, revised retrieval algorithm (Dubovik et al., 2002b) which treats the aerosols as a mixture of spherical and spheroid particles and minimize most of these artefacts has been used.

The availability of the AERONET size-distribution data corresponding to the impactor sampling periods throughout the two-years was $81 \%$. On a seasonal basis the coverage was $67 \%$ for winter, $68 \%$ for autumn, $92 \%$ for spring while during summer the correspondence reaches $100 \%$.

\section{Total mass}

\subsection{Data set presentation}

The SDI samplings cover two full years (July 2004-July 2006). During this period a number of 89 samples have been collected equally distributed throughout the seasons. The $\mathrm{PM}_{10}, \mathrm{PM}_{2.5}$ and $\mathrm{PM}_{1}$ fractions are presented in Fig. 1, together with the $\mathrm{PM}_{10}$ from the Eberline Particulate Monitor. $\mathrm{PM}_{10}$ and $\mathrm{PM}_{2.5}$ show greater sample-to-sample variability than $\mathrm{PM}_{1}$ which is related to their different origin as will be shown in the following sections. Basic statistical information for the different fractions of PM and their in-between ratios is included in Table 1. Overall, the $\mathrm{PM}_{10}$ two-year average from the SDI is $31 \mu \mathrm{g} \mathrm{m}^{-3}$, for $\mathrm{PM}_{2.5}$ it is $18 \mu \mathrm{g} \mathrm{m}^{-3}$ (about $60 \%$ of $\mathrm{PM}_{10}$ ) and for $\mathrm{PM}_{1}$ it is $10 \mu \mathrm{g} \mathrm{m}^{-3}$ (about $40 \%$ of 

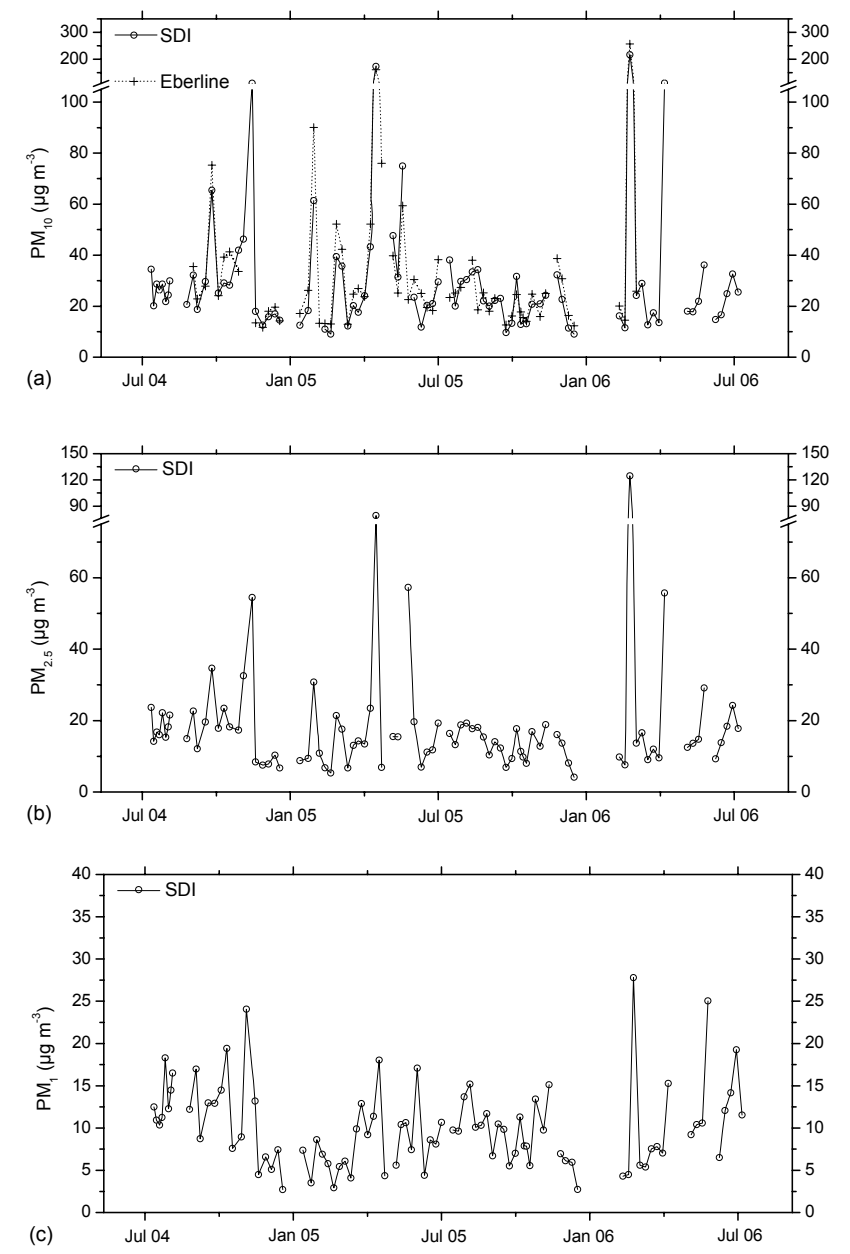

Fig. 1. $\mathrm{PM}_{10}, \mathrm{PM}_{2.5}$ and $\mathrm{PM}_{1}$ fractions measured at Finokalia for the period July 2004-July 2006 using the SDI and the Eberline FH 62 I-R Particulate Monitor.

$\mathrm{PM}_{10}$ ). The here reported $\mathrm{PM}_{10}$ values from a gravimetric technique are in very good agreement with the values recently reported for Crete, during a 5-year period (Gerasopoulos et al., 2006). $\mathrm{PM}_{2.5}$ mean value is also in good agreement with the values reported for Sde Boker, Israel, (the only longterm study performed so far in the eastern Mediterranean; Andreae et al., 2002) as well as with those reported for rural sites around the western basin (Rodriguez et al., 2002; Querol et al., 2004). No long-term work has been previously performed in the Mediterranean concerning the $\mathrm{PM}_{1}$ fraction. The $\mathrm{PM}_{1}$ levels during summer and winter are in the range of the values reported by Smolik et al. (2003) for Finokalia in July 2001 and January 2002.

\subsection{Comparison between the different fractions of PM}

The $\mathrm{PM}_{10}$ masses from the SDI are checked against $\mathrm{PM}_{10}$ from the $\beta$-attenuation particulate monitor operating at Finokalia station on a continuous basis. $\mathrm{PM}_{10}$ from the $\beta$ -

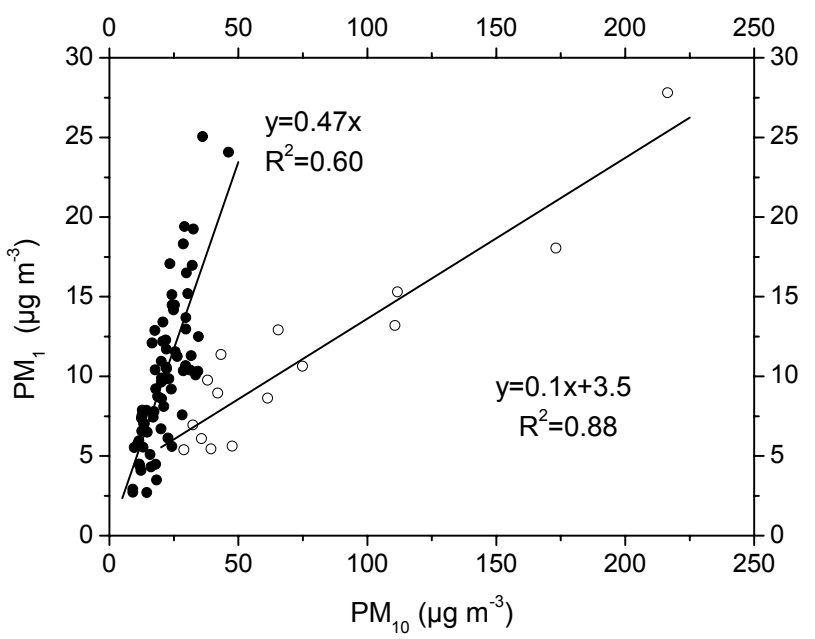

Fig. 2. $\mathrm{PM}_{1}$ versus $\mathrm{PM}_{10}$ during the two year sampling period of the SDI. Data influenced by dust are shown as open circles and regression lines are calculated for each case.

attenuation is averaged to correspond to the sampling duration of each SDI set. The comparison between the SDI and the $\mathrm{PM}_{10}$ monitor revealed a very good correlation $\left(\mathrm{R}^{2}=0.95\right.$; not shown), with a slope of 1.08 showing a slight under estimation of the $\mathrm{PM}_{10}$ masses from the SDI. This intercomparison provided a useful tool for the estimation of the uncertainty of the masses measured via the very sensitive weighting procedure of the SDI stages.

The relation between the different fractions of the particulate matter as derived from the SDI measurements is further investigated. A significant correlation between $\mathrm{PM}_{2.5}$ and $\mathrm{PM}_{10}\left(R^{2}=0.94\right.$; not shown $)$ with a slope of 0.55 suggests that the $\mathrm{PM}_{2.5}$ and $\mathrm{PM}_{10}$ fractions of particulate matter in the area have common variability. A much weaker correlation is found between $\mathrm{PM}_{1}$ and $\mathrm{PM}_{10}$ (Fig. 2). In particular, two groups of data are formed with the one demonstrating higher $\mathrm{PM}_{10}$ levels for the same $\mathrm{PM}_{1}$ values. This is related to transported dust and shows a significant correlation $\left(R^{2}=0.88\right)$. The slope of 0.1 of this group coincides with the minimum $\mathrm{PM}_{1} / \mathrm{PM}_{10}$ values (Table 1) pointing out that during dust events the coarse particles dominate (90\%) the $\mathrm{PM}_{10}$ mass. The second group shows a slope of 0.47 (higher than the average $\mathrm{PM}_{1} / \mathrm{PM}_{10}$ ratio in Table 1 which includes dust events), however the relatively poorer correlation $\left(R^{2}=0.60\right)$ depicts the lack of covariance between the two fractions due to the different sources of the submicron particles.

\subsection{Seasonality of the different fractions of PM}

The seasonal variability of $\mathrm{PM}_{10}, \mathrm{PM}_{2.5}$ and $\mathrm{PM}_{1}$ is shown in Fig. 3. Two types of variability measure are introduced in Fig. 3; the standard deviation of all samples within the two year sampling period (error bars), and the standard deviation between the monthly averages of each year (dotted line), 

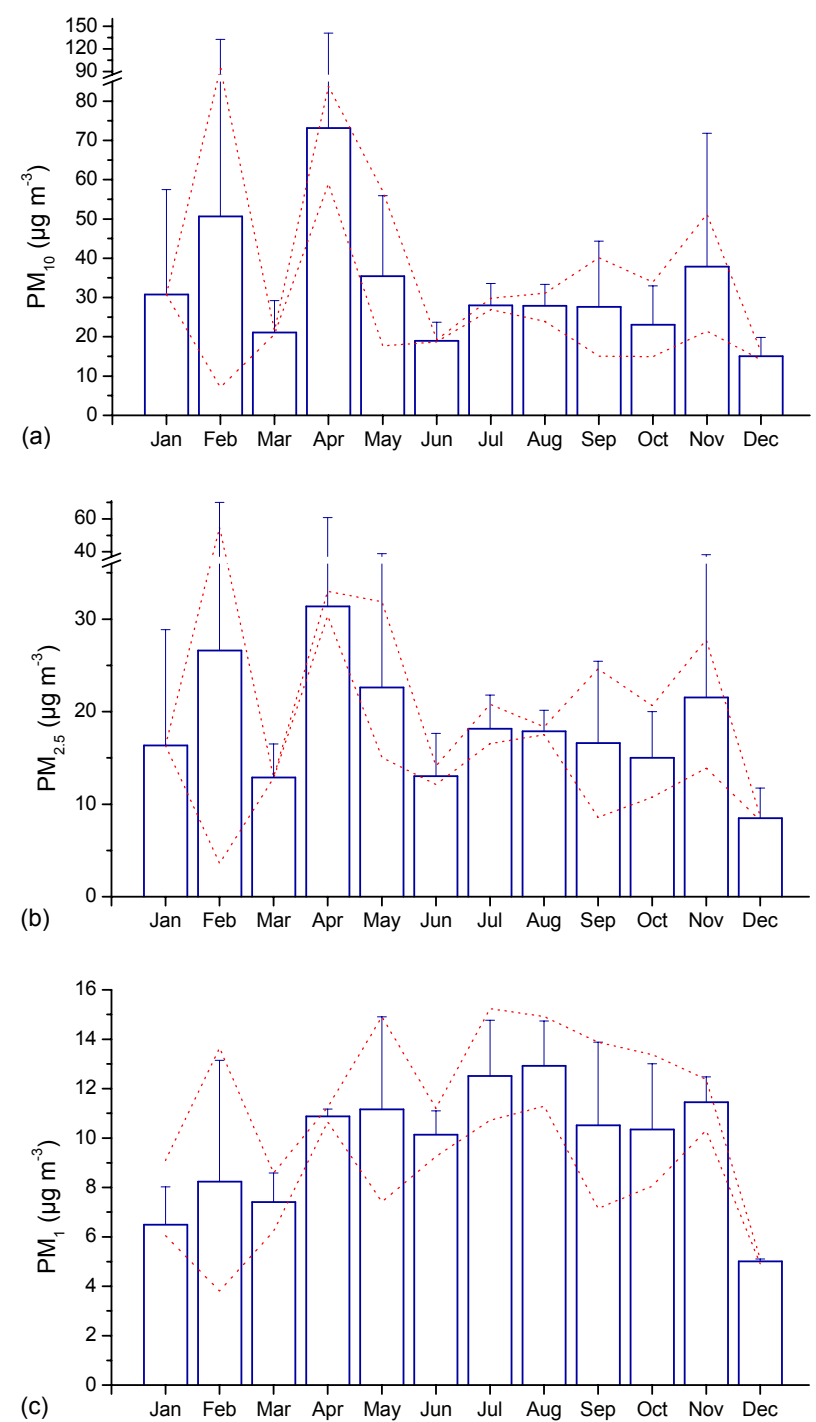

Fig. 3. Seasonal cycles of (a) $\mathrm{PM}_{10}$, (b) $\mathrm{PM}_{2.5}$ and (c) $\mathrm{PM}_{1}$ fractions at Finokalia derived from the SDI measurements during the period July 2004-July 2006. The error bars correspond to the standard deviation of all samples within the two year period, while the dotted lines correspond to the standard deviation between the monthly averages of each year.

indicating the sample-by-sample and the month-by-month variability, respectively. $\mathrm{PM}_{10}$ masses present a prominent peak in spring (April) and a secondary one in February. The spring maximum is due to the increased frequency of dust transport from northern Africa, while the peak in February is due to an intense dust event occurring in 2006, also denoted by the high standard deviation (Fig. 3a). The factors that control $\mathrm{PM}_{10}$ levels and variability over the area are described in detail by Gerasopoulos et al. (2006). $\mathrm{PM}_{2.5}$ present similar seasonal features, however the observed peak in April is moderate compared to that of $\mathrm{PM}_{10}$, demonstrating the dominance of coarse particles during the dust events (Fig. 3b).

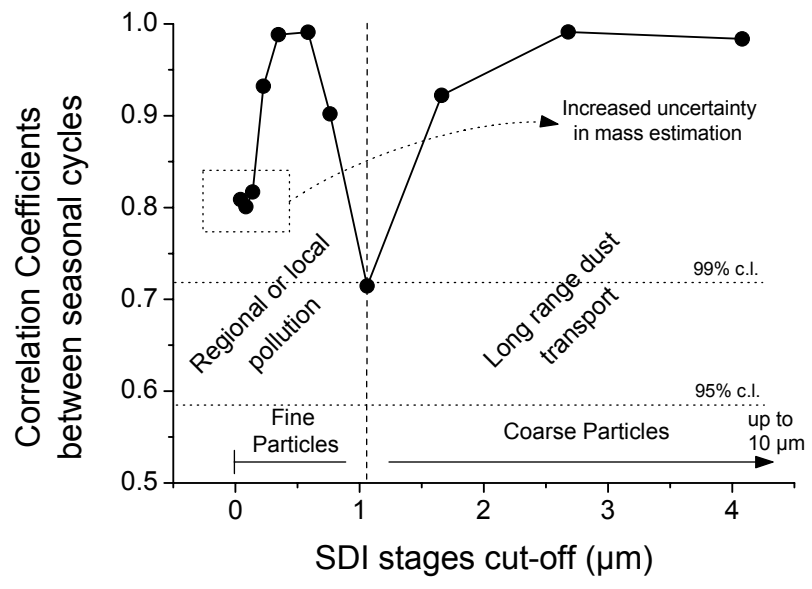

Fig. 4. Correlation coefficients between the seasonal cycles from the adjacent stages of the SDI. The coefficient is attributed to the stage with the lower cut-off. The 99 and $95 \%$ confidence levels of the correlation coefficients are represented by the horizontal dotted lines.

However, the similar seasonality between the two fractions is indicative of common sources which in spring is mainly dust transported from Africa. Finally, the situation is different for the $\mathrm{PM}_{1}$ fraction. $\mathrm{PM}_{1}$ presents a summer maximum with monthly values up to $13 \mu \mathrm{g} \mathrm{m}^{-3}$ (up to almost $30 \mu \mathrm{g} \mathrm{m}^{-3}$ for individual impactor samplings; Table 1), which expresses a significant number of submicron particles from regional or long-range transported pollution (Fig. 3c).

In order to investigate in more detail the "key" particle diameter at which different sources (e.g. dust, pollution) control the variability of the various particulate matter fractions, the seasonal cycles for all SDI stages were derived (not shown). Then, correlation coefficients between the seasonal cycles from adjacent SDI stages were calculated (Fig. 4). It is evident that the seasonal cycles of all stages above $1 \mu \mathrm{m}$ are highly correlated, indicative of the dominance of dust particles in the coarse mode mainly during spring. The fine mode is controlled by pollution related particles and their sources show a broader seasonality. The correlation between the lower stages is relatively reduced (but still statistically significant), and this probably reflects the enhanced uncertainty in measuring such low masses rather than distinct sources.

From the above results it is evident that simultaneous monitoring of $\mathrm{PM}_{10}$ and $\mathrm{PM}_{1}$ could provide adequate description of near-background particulate matter in the Mediterranean atmosphere. This result should be taken under consideration for policy making and abatement strategies for man-made aerosol reduction, even though it should be checked whether this result is valid also for important urban centers of the area (e.g. in the case of Athens). 


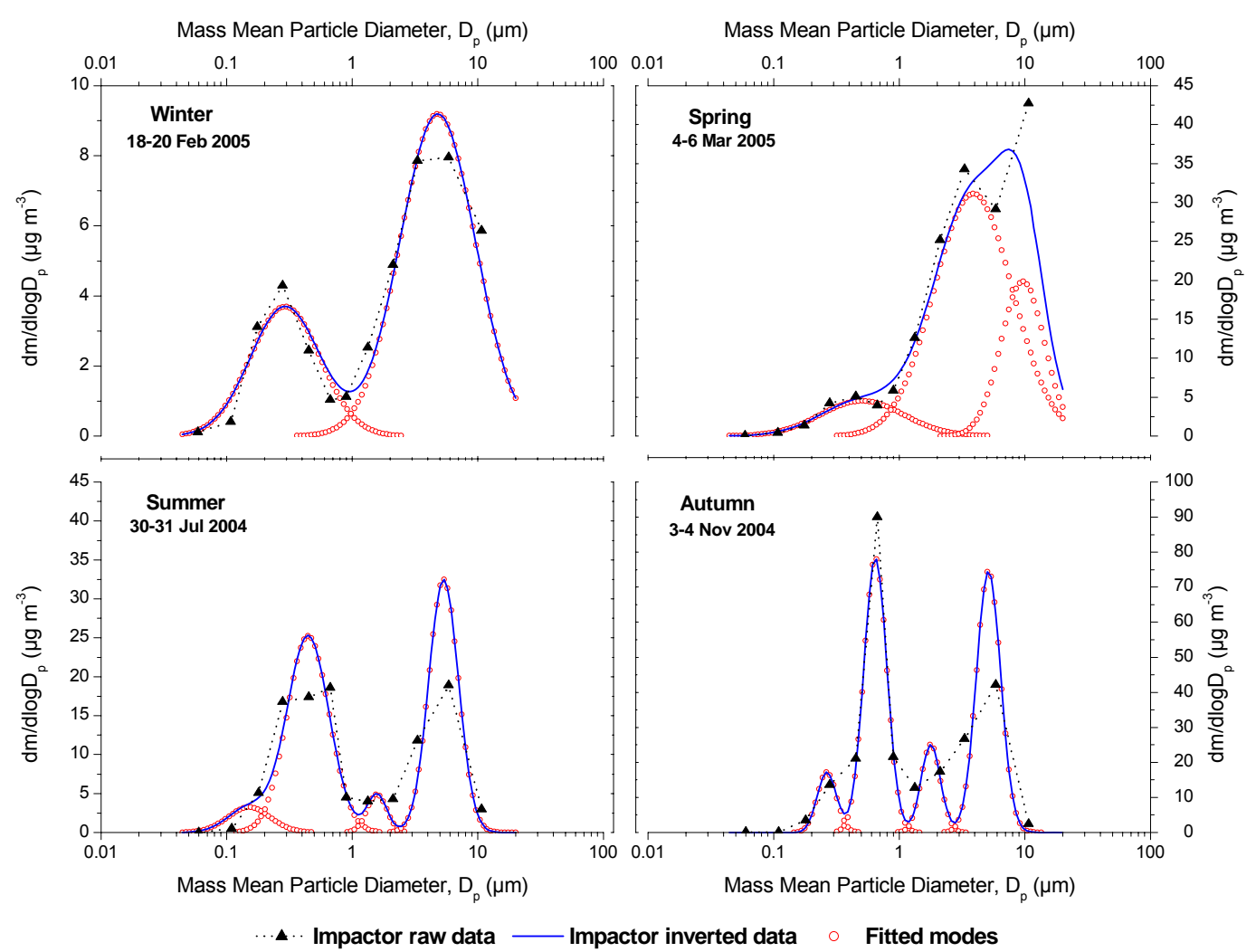

Fig. 5. Typical examples of mass distributions per season. The plots include raw gravimetric stage mass concentrations (impactor raw data) and continuous distributions after applying the collection efficiency curves of the impactor (inversion - impactor inverted data) on the raw data. Finally, a number of lognormal distributions are fitted to separate between the different modes of each distribution.

\section{Size-segregated mass}

4.1 Typical mass size distributions and statistical assessment

The size-resolved mass distributions derived from the SDI impactor data were additionally studied. Continuous mass size-distributions were obtained through the MICRON inversion code (Wolfenbarger and Seinfeld, 1990) and example distributions were chosen for each season and are presented in Fig. 5. In the winter case (18-20 February 2005), a low particle loading is observed with two distinct modes at 0.3 and $5 \mu \mathrm{m}$, respectively. In the spring case (4-6 March 2005), the fine mode is of the same amplitude, however enhanced concentration is found at the $4 \mu \mathrm{m}$ mode (note the different scales) and even coarser particles appear at around $10 \mu \mathrm{m}$. The latter could be related to the presence of coarse dust particles. Moving to the summer case (30-31 July 2004), the two main modes are again observed, with more mass contained in the fine one, while two more modes can be seen at about 0.15 and $1.5 \mu \mathrm{m}$, respectively. The enhanced particle formation in summer, or the processes that can modify the particle size and composition, are the possible reasons of the multiple modes corresponding to the fine size fraction of this distribution. Finally, in the autumn case (3-4 November 2004), enhanced concentration at both the submicron and supermicron fractions are observed, pointing out the coexistence of dust particles with pollution, while different modes in the fine area can be once more observed.

Log-normal distributions were fitted on the continuous mass size distributions using the following equation:

$$
\begin{aligned}
& \frac{d m}{d \log _{10} D_{p}}=\sum_{i=1}^{n} \frac{M_{i}}{\sqrt{2 \pi} \log _{10} \mathrm{GSD}_{i}} . \\
& \quad \exp \left[-\frac{\left(\log _{10} D_{p}-\log _{10} \mathrm{MMD}_{i}\right)^{2}}{2 \cdot \log _{10}^{2} \mathrm{GSD}_{i}}\right]
\end{aligned}
$$

where MMD and GSD correspond to the Mass Mean Diameter (aerodynamic) and the Geometric Standard Deviation of each log-normal distribution, and $\mathrm{M}$ to the total mass of the specific mode. The presence of the different aerosol modes in the 89 distributions acquired with the SDI during the period July 2004-July 2006 is statistically approached in Fig. 6.

In Fig. 6a, the frequency of occurrence of the calculated Mass Mean Diameter (MMD) is plotted, in order to provide information on the number and the size ranges of the different modes. Seven aerosol modes are evident: A: Aitken 1 

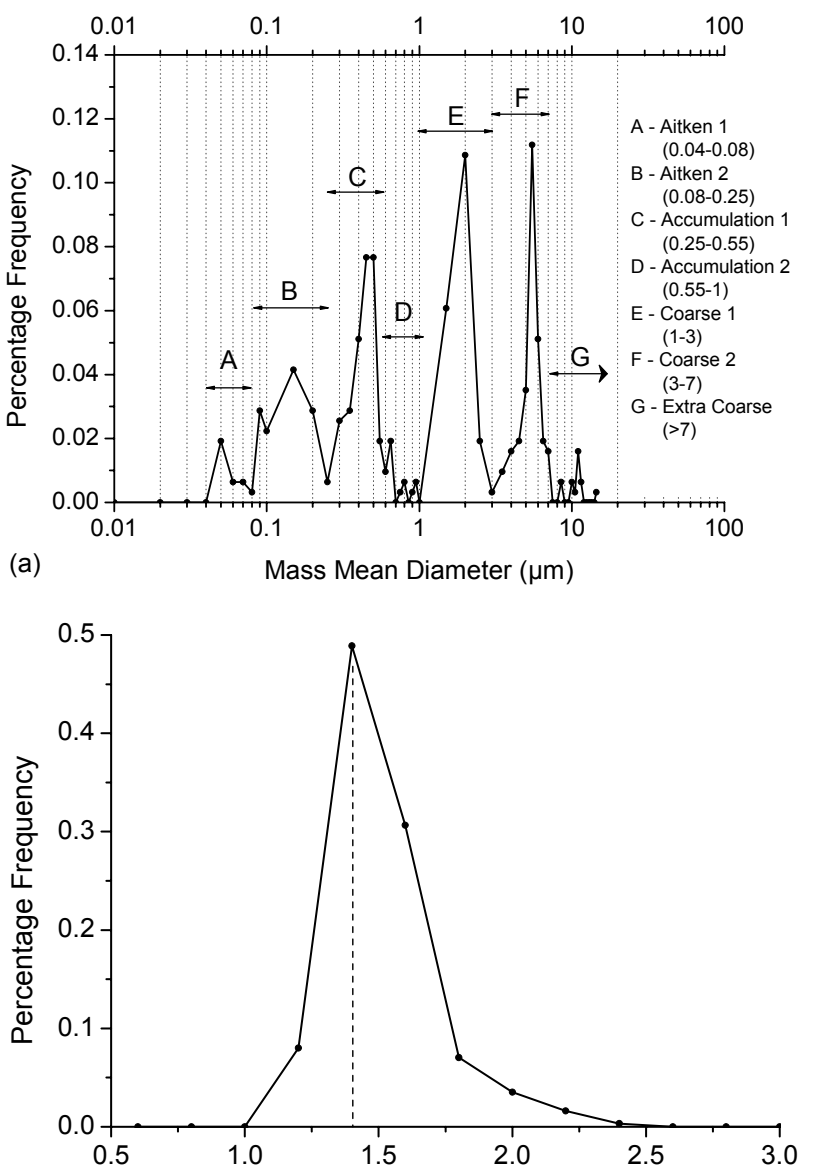

(b)

Geometric Standard Deviation

Fig. 6. Frequency distribution of the (a) mass mean diameter (MMD) and (b) geometric standard deviation (GSD) of all mass modes that have been identified and fitted by lognormal distributions from a total of 89 SDI samplings.

(0.04-0.08 $\mu \mathrm{m})$, B: Aitken $2(0.08-0.25 \mu \mathrm{m})$, C: Accumulation $1(0.25-0.55 \mu \mathrm{m})$, D: Accumulation $2(0.55-1 \mu \mathrm{m})$, E: Coarse 1 (1-3 $\mu \mathrm{m})$, F: Coarse $2(3-7 \mu \mathrm{m})$ and G: Extra Coarse $(>7 \mu \mathrm{m})$. The uppermost mode can show up in the measurements only partly, because the $\mathrm{PM}_{10}$ inlet will cut off the particles larger than $10 \mu \mathrm{m}$. Also, it should be mentioned that the Aitken 1 mode $(\mathrm{A})$ is related to rather low measured masses with therefore enhanced uncertainty. However, we have retained this mode in the analysis, since at this size range an imperceptible mass mode could correspond to a significant number of particles. The frequency distribution of the geometric standard deviations (GSD) of all log-normal fittings on the observed modes has been additionally calculated (Fig. 6b). The distribution of GSDs approximates the normal distribution and for all fittings that the GSD of an individual mode laid above 2.0 an attempt to fit two log-normal distributions was made.
Using the fitted, continuous distributions, the deviation of the SDI PM $\mathrm{PM}_{2.68}$ and $\mathrm{PM}_{1.06}$ from the usually reported $\mathrm{PM}_{2.5}$ and $\mathrm{PM}_{1}$ was additionally estimated. Within individual impactor samples, the mass difference has an interquartile range 2-5\% (maximum 12\%) for $\mathrm{PM}_{2.5}$, while for $\mathrm{PM}_{1}$ the interquantile range is $1-2 \%$ (maximum 15\%). Maxima are encountered when a mode is found at the right and very close to 1 and $2.5 \mu \mathrm{m}$, respectively. On average, $\mathrm{PM}_{2.68}$ is $3-4 \%$ higher than $\mathrm{PM}_{2.5}$ and $\mathrm{PM}_{1.06}$ is $1-2 \%$ higher than $\mathrm{PM}_{1}$. This is reflected as $0.5-0.7$ and $0.1-0.2 \mu \mathrm{g} \mathrm{m}^{-3}$ additional mass in the reported averages (Table 1), which is well within the error of the weighting process and the sample-by-sample variability.

\subsection{Seasonal variability of the different aerosol modes}

The seasonal characteristics of the seven different modes of aerosols were additionally investigated. Figure 7 provides information on the average mass of each mode throughout the year, as well as their frequency of occurrence in the mass size distributions of each season. Average masses were preferred to medians, so that the effect of the various sources would be clearly depicted rather than smoothed by background distribution patterns.

The submicron part of the mass distributions is dominated by the "Accumulation 1" mode (Fig. 7a) at $0.41 \pm 0.07 \mu \mathrm{m}$ (average \pm standard deviation). This mode is observed in almost all impactor samples (a few exceptions in spring), and presented a pronounced seasonality with a maximum in summer, more than twofold the observed minimum in winter. In summer, the mode-mass goes up to $19 \mu \mathrm{g} \mathrm{m}^{-3}$,possessing even $68 \%$ of the total mass, in coincidence with the enhanced transport of pollution from continental Europe during that period (Gerasopoulos et al., 2005). The second most frequent mode is "Aitken 2" at $0.12 \pm 0.04 \mu \mathrm{m}$, which is present in about half of the samples in summer and autumn; however its contribution to the total impactor mass appears low. It presents a summer maximum, and its maximum contribution to the total mass is $34 \%$. The "Accumulation 2" mode at $0.71 \pm 0.17 \mu \mathrm{m}$ is the next most frequent in the submicron group, present in almost one quarter of the distributions in summer and autumn. However when present, it includes a significant part of the fine particles mass, which in autumn balances the mass contribution of the "Accumulation 1 " mode. Finally, the "Aitken 1" mode at $0.05 \pm 0.01 \mu \mathrm{m}$ is found in $12 \%$ of the samples on an annual basis, but never in spring, and its average mass peaks in summer, as the majority of the submicron modes. A reason for the absence of the "Aitken 1" mode in spring could be that such fine particles can stick rapidly to the numerous coarse dust particles that are present this season in the atmosphere.

Overall, the modes of the fine part of the mass distributions present a summer maximum concerning the mass of the mode, and do not show any particular seasonal preference concerning their occurrence. They are thus related to 

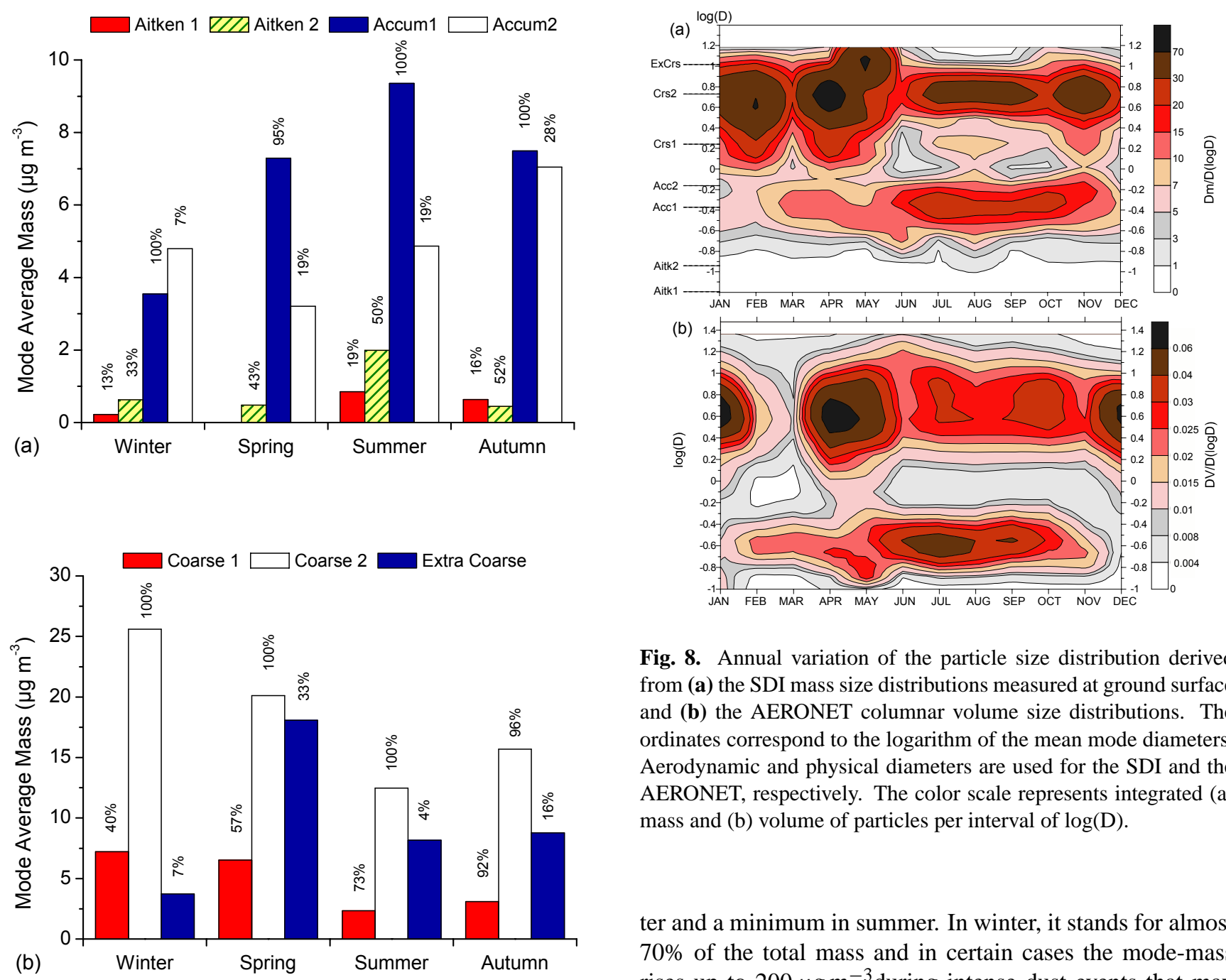

Fig. 8. Annual variation of the particle size distribution derived from (a) the SDI mass size distributions measured at ground surface and (b) the AERONET columnar volume size distributions. The ordinates correspond to the logarithm of the mean mode diameters. Aerodynamic and physical diameters are used for the SDI and the AERONET, respectively. The color scale represents integrated (a) mass and (b) volume of particles per interval of $\log (\mathrm{D})$.

Fig. 7. Seasonal variability of the average mass of each mass mode for the period July 2004-July 2006. The modes are presented separately for the fine (a) and the coarse (b) fractions. Numbers on the top of the columns indicate the frequency of occurrence of that mode into the distributions.

regional sources of pollution that enhances during summer via more intense transport from the main European continent. To this conclusion the "Accumulation 2" mode is the exception since it is more frequent in autumn and also its mass maximizes in autumn. Growth of smaller particles by oxidation is probably not the mechanism that creates these particles. On the other hand, it is possible that $\mathrm{CCN}$ in drops that grow by coalescence and then evaporate can lead to the release of larger particles into the atmosphere (Meng and Seinfeld, 1994; Kerminen and Wexler, 1997).

In the supermicron part of the mass distributions (Fig. 7b), the "Coarse 2" mode at $5.2 \pm 0.7 \mu \mathrm{m}$ is dominant, since it is observed in almost all samples (a few exceptions in autumn). The average mass of the mode presents a maximum in win-

ter and a minimum in summer. In winter, it stands for almost $70 \%$ of the total mass and in certain cases the mode-mass rises up to $200 \mu \mathrm{g} \mathrm{m}^{-3}$ during intense dust events that may occur also in winter. Taking into account the medians of the "Coarse 2" mode masses instead of averages, then the difference between winter and spring is diminished, demonstrating the fact that dust events may be more frequent in spring but in winter the majority presents a more homogeneous vertical distribution thus inducing higher loading down to the surface (VET-Vertically Extended Transport; Kalivitis et al., 2006). The "Coarse 1" mode at $1.7 \pm 0.4 \mu \mathrm{m}$ is found in $70-90 \%$ of the summer and autumn samples and $40-60 \%$ in winter and spring, nevertheless, its contribution to the total mass is more significant in winter and spring. Finally, an "Extra Coarse" mode at $10.5 \pm 1.5 \mu \mathrm{m}$ is observed in spring (33\%; and secondarily in autumn). During spring it can stand for up to $60 \%$ of the total mass, the maximum mass of this mode does not exceed $43 \mu \mathrm{g} \mathrm{m}^{-3}$ and it is always found simultaneously with the "Coarse 2" mode. This might imply gravitational scavenging of the coarser particles during dust events. Preliminary results from the chemical analyses performed for each impactor stage, has revealed that the "Coarse 2" and the "Extra Coarse" modes are related to dust, while the "Coarse 1 " mode is probably attributed to sea salt. 
4.3 Surface, mass size distributions versus AERONET, columnar, volume size distributions

\subsubsection{Annual variation of particle size distribution from the SDI and AERONET}

The annual variation of the particle size distributions averaged over a month is shown in Fig. 8. In Fig. 8a, the average mass size distributions from the SDI samplings per month were used as representative of the surface distributions, and in Fig. $8 \mathrm{~b}$ the average volume size distributions obtained from the AERONET-FORTH sun photometer were deployed to introduce the columnar information. Similar procedure using the AERONET data has been applied from Israelevich et al. (2003) for desert dust aerosol over Israel. It should be noted that the SDI provides mass distributions based on the aerodynamic diameter of the particles, while the AERONET volume distributions refer to physical or stokes diameter (identical for smooth, spherical particles). The relation between the two types of diameters is given by the following equation:

$d_{\text {aerod }}=d_{\text {phys }} \cdot \sqrt{\rho}$

where $\rho$ is the particle density in $\mathrm{g} \mathrm{cm}^{-3}$. Equation (2) is valid for particles greater than $0.5 \mu \mathrm{m}$ (slip correction is acquired for much smaller particles) and thus aerodynamic diameters are in principle greater than physical diameters. Comparison of the color scales between the surface and columnar patterns should be also considered with caution because of the different units.

The two diagrams show significant similarities and agree well with the discussion of the modes seasonality based on Fig. 7. Thus, distinct coarse patterns are revealed in spring (March-May), in agreement with the increasing frequency of dust transport. Similarities are also found in winter, however the columnar volume distributions show a broader winter pattern (November-January) than the surface mass distributions which is displaced to late winter (January-February). Less mass or volume is found in the coarse mode during summer and autumn. At the surface, the picture for the coarse fraction is more homogenous throughout the year, possibly because of the presence of sea salt aerosols at the coastal station, while the columnar data depict more clearly the presence of dust. An extra coarse mode appears in late spring at the mass size distributions from the SDI. Significant similarities are also found in the fine mode. The summer-autumn fine particle pattern is apparent in both diagrams and even a trend to finer particles from winter towards spring can be observed.

Overall, a very good agreement is revealed between the AERONET volume size distributions and the mass size distributions derived from the impactor, denoting that the latter can provide significant information on the columnar distribution of the size resolved characteristics of particulate matter in the area.
4.3.2 Correspondence between surface and columnar characteristics for the fine and coarse aerosol modes

The difference of the fine or coarse mode mean-diameters between the surface-mass and columnar-volume distributions is further investigated. For this reason the physical diameters of the AERONET distributions were first converted to aerodynamic diameters using Eq. (2) and applying different mean densities for the fine and the coarse particles. In particular, considering the fine mode as a mixture of mainly ammonium sulfate $\left(\rho=1.75 \mathrm{~g} \mathrm{~cm}^{-3}\right.$; Lide, 1991) and organics $\left(\rho=1.2 \mathrm{~g} \mathrm{~cm}^{-3}\right.$; Turpin and Lim, 2001), we have applied a mean density of $1.5 \mathrm{~g} \mathrm{~cm}^{-3}$ for the fine mode, and a mean density of $2 \mathrm{~g} \mathrm{~cm}^{-3}$ for the coarse mode as representative of dust particles (Tegen et al., 2006). In the case of AERONET distributions, the fine and coarse modes are discrete, while in the case of the impactor, the MMDs for the "Accumulation 1 " and "Coarse 2" modes were used. The frequency distribution of the difference between the MMDs from the impactor and the Volume Mean Diameter by AERONET, henceforth referred to as Diff_Diameter, is presented in Figs. 9a and b for the fine and coarse modes, respectively.

The Diff_Diameter of the fine mode follows a normal distribution with a central value around $0.1 \mu \mathrm{m}$, demonstrating that the impactor sample somewhat coarser particles than those found in the column. Since the fine particles are related mainly to anthropogenic sources found near surface, it might be that AERONET perceives a reduced, integrated, mean diameter due to the vertical distribution of aerosols. This is strengthened by the fact that in winter and spring, when pollution is low, the difference shifts to the lower values of the distribution, while in summer and autumn, when pollution peaks, the difference shifts to higher values. Moreover, the increased water vapor mixing ratios into the mixing layer results to hygroscopic growth of certain particles that could partly explain the observed difference of the fine mode diameters.

For the coarse fraction a bimodal pattern is formed, each mode following a normal distribution centered at 0 and -6.4 . The first class of Diff_Diameter indicates the very good agreement between the AERONET and the impactor distributions concerning the mean diameter of the coarse particles. The negative class represents the cases when AERONET perceives larger particles in the column than the SDI at the surface, and these cases were mainly observed during summer. This is in full agreement with Kalivitis et al. (2006), who have shown that in summer the Free Tropospheric Transport of dust is the dominant mechanism of dust transport over the area; and the increase in diameter with the height points out the presence of elevated dust layers in the free troposphere.

The total mass of the fine and coarse modes (separated at $1 \mu \mathrm{m}$ ) derived from the SDI are plotted versus the corresponding total volume from the AERONET distributions (Fig. 10). This offers the opportunity to investigate the extent at which the ground based measurements can capture the 

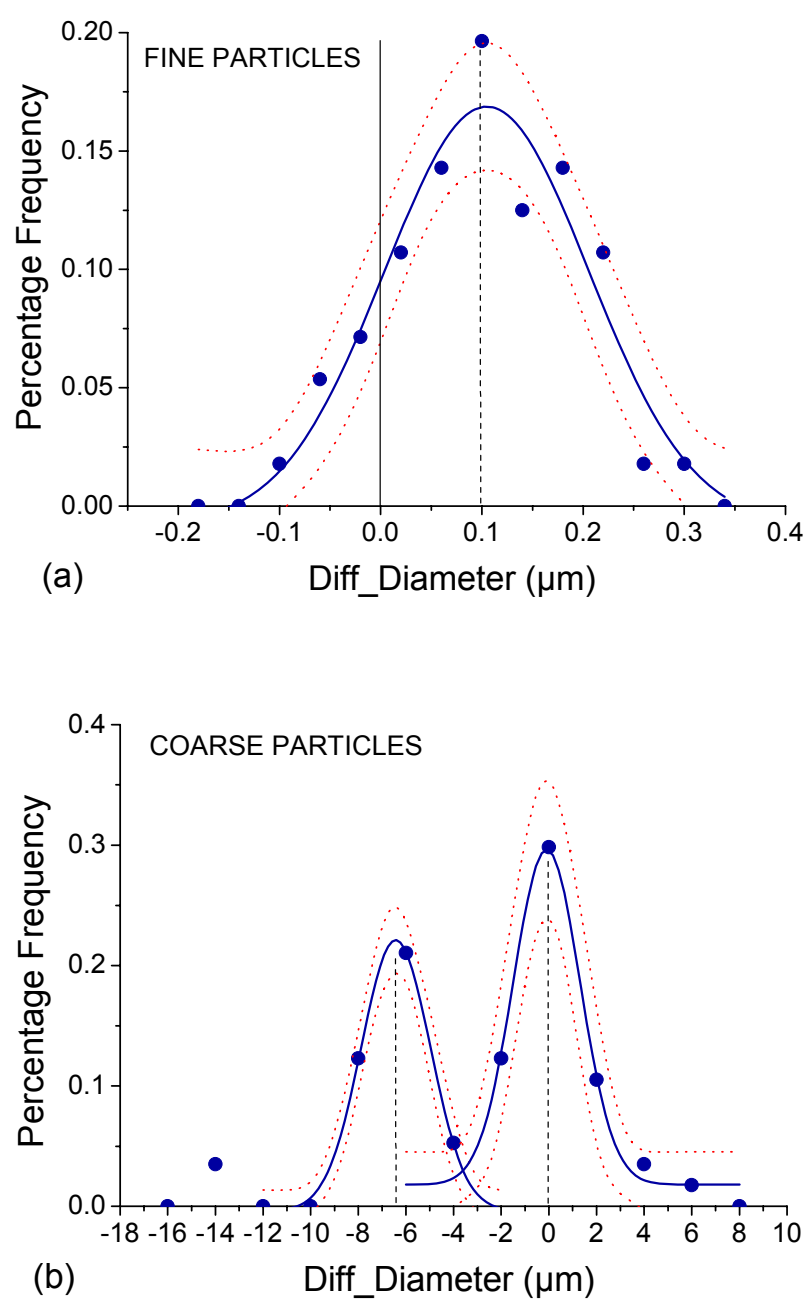

Fig. 9. Frequency distribution of the difference between the mass mean diameter derived from the SDI and the corresponding AERONET distribution (Diff_Diameter) for the fine particle (a) and the coarse particle (b) modes. The AERONET distribution physical diameters were first converted to aerodynamic diameters (see text).

characteristics of the fine and the coarse particles in the column, and at the same time whether the remote sensing technique is adequate to represent inside boundary layer loadings.

A good correlation is revealed when year-round data are used $\left(R^{2}=0.48\right.$, significant at the $99 \%$ confidence level) for the fine mode (Fig. 10a). The extracted linear regression line enables the estimation of the ground based fine fraction mass from the AERONET volume size distributions, with an error of $12-18 \%$ for the range of $0.01-0.1$ of the total fine particle volume. Of course, it should be kept in mind that in the case of episodic peaks of fine particle loadings near surface, AERONET's lower temporal coverage could result to greater uncertainty in the above estimation.
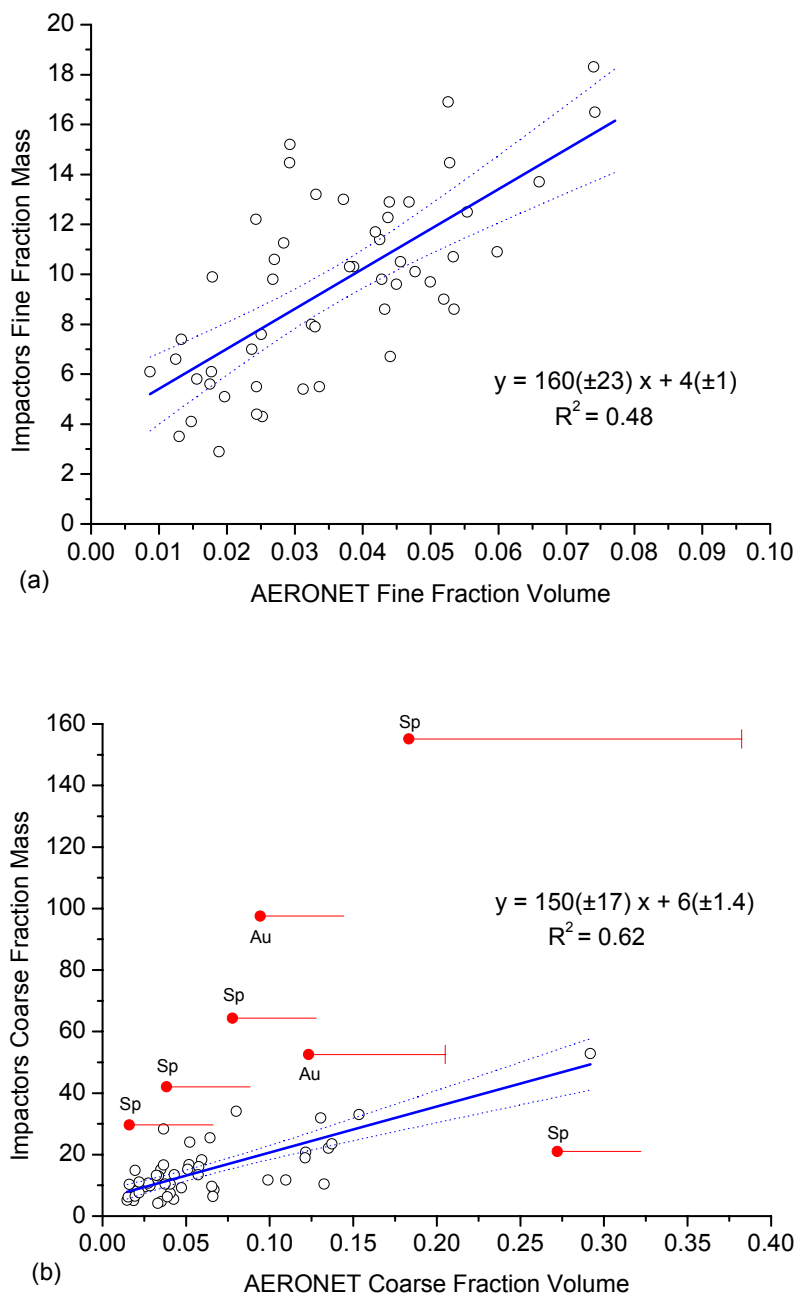

Fig. 10. Scatterplot between the total mass from the SDI and the total volume from AERONET for the fine (a) and the coarse (b) fractions of particles. Linear regression lines are fitted on data (numbers in parentheses correspond to the standard error of the estimated parameter). Points considerably departing from the regression line (b) are distinguished (red) and accompanied by a horizontal error bar (no line cap: only one measurement available, with line cap: standard deviation of the averages). "Sp" and "Au" correspond to spring and autumn.

The picture is more complicated in the case of the coarse mode. Although a significant covariance is found for the coarse mode as well $\left(R^{2}=0.62,99 \%\right.$ c.l., Fig. $\left.10 \mathrm{~b}\right)$, there are some points along a steeper regression line. The main regression line for the coarse mode is similar to that observed for the fine one, and enables the estimation of the ground based coarse fraction mass from the AERONET volume size distributions, with an error of about $10 \%$ for the range of $0.1-0.3$ of the total coarse particle volume. The departing points are mostly found in spring and autumn, when the intense dust transport occurs, and correspond to cases when either only one AERONET measurement was available 
during the impactor sampling or the standard deviation of the AERONET averages was high ( $>70 \%$ of the average). There is also one spring case lying below the regression line, possibly characteristic of a Free Tropospheric case of dust transport not captured by the ground measurements.

\section{Summary and conclusions}

A two-year data set (2004-2006) of mass distributions from size-selective samplings was used to extract the modal characteristics of particulate matter in the environment of Eastern Mediterranean. The seasonal pattern of the different fractions of particulate matter has revealed different sources for submicron and supermicron particles, the first being related to local/regional and transported pollution and the latter to dust from deserted areas in Northern Africa. As a consequence, the simultaneous monitoring of only $\mathrm{PM}_{10}$ and $\mathrm{PM}_{1}$ could provide an adequate description of near background particulate matter levels in the Mediterranean area, and this result should be taken under consideration for policy making and abatement strategies towards a decrease of airborne particles levels.

Seven distinct modes were identified in all acquired distributions. The most important by means of frequency of occurrence and contribution to the total mass were the "Accumulation 1" $(0.25-0.55 \mu \mathrm{m})$ and the "Coarse 2" (3-7 $\mu \mathrm{m})$ modes. The seasonal characteristics of the different modes agreed well with the discrimination of the various sources namely dust transport from the south mainly in spring and pollution during summer.

The volume size distributions of aerosols derived from AERONET, representative of the columnar characteristics of aerosols, were additionally validated with the surface mass size distributions from the impactor. Similar patterns were found between the two approaches concerning the seasonal characteristics of the size segregated aerosols. In particular, distinct coarse patterns were revealed in spring and winter, in agreement with the increasing frequency of dust transport during spring, while the fine modes presented their maxima in summer. Finally, the ground-based measured mass and columnar volume of the fine and the coarse modes, respectively, were significantly correlated, indicating first that ground based measurements provide a reasonable picture of the columnar distributions of aerosols and second that remote sensing data from AERONET can be used in the estimation of background levels of both fine and coarse particles. Limitations are initiated in the case of abrupt episodes of either pollution or dust, due to the low temporal coverage provided by AERONET.

The chemical composition of the SDI samples will help us to elucidate the relation between the mass distributions from size-selective ground samplings and AERONET data.
Acknowledgements. The project is co-funded by the European Social Fund and National resources (PYTHAGORAS I). The Academy of Finland (contract no. 201131) financial support is gratefully acknowledged by the Finnish team. Sanna Saarikoski also thanks the Maj and Tor Nessling Foundation for the financial support. We thank B. Holben (NASA-GSFC) for providing us the Sun photometer within the framework of the AERONET program and I. Vardavas for his effort in establishing and maintaining the Aeronet FORTH_CRETE site.

Edited by: A. Nenes

\section{References}

Andreae, T. W., Andreae, M. O., Ichoku, C., Maenhaut, W., Cafmayer, J., Karnieli, A., and Orlovsky, L.: Light Scattering by dust and anthropogenic aerosol at a remote site in the Negev Desert, Israel, J. Geophys. Res., 107(D2), 4008, doi:10.1029/2001JD900252, 2002.

Dubovik, O. and King, M. D.: A flexible inversion algorithm for retrieval of aerosol optical properties from Sun and sky radiance measurements, J. Geophys. Res., 105, 20 673-20 696, 2000.

Dubovik, O., Smirnov, A., Holben, B. N., King, M. D., Kaufman, Y. J., Eck, T. F., and Slutker, I.: Accuracy assessments of aerosol optical properties retrieved from Aerosol Robotic Network (AERONET) Sun and sky radiance measurements, J. Geophys. Res., 105, 9791-9806, 2000.

Dubovik, O., Holben, B. N., Eck, T. F., Smirnov, A., Kaufman, Y. J., King, M. D., Tanre, D., and Slutsker, I.: Variability of absorption and optical properties of key aerosol types observed in worldwide locations, J. Atmos. Sci., 59, 590-608, 2002a.

Dubovik, O., Holben, B. N., Lapyonok, T., Sinyuk, A., Mishchenko, M. I., Yang, P., and Slutsker, I.: Non-spherical aerosol retrieval method employing light scattering by spheroids, Geophys. Res. Lett., 29(10), 1415, doi:10.1029/2001GL014506, 2002 b.

Gerasopoulos E., Andreae, M. O., Zerefos, C. S., Andreae, T. W., Balis, D., Formenti, P., Merlet, P., Amiridis, V., and Papastefanou, C.: Climatological aspects of aerosol optical properties in Northern Greece, Atmos. Chem. Phys., 3, 2025-2041, 2003, http://www.atmos-chem-phys.net/3/2025/2003/.

Gerasopoulos, E., Kouvarakis, G., Babasakalis, P., Vrekoussis, M., Putaud, J. P., and Mihalopoulos, N.: Origin and variability of particulate matter (PM10) mass concentrations over the Eastern Mediterranean, Atmos. Environ., 40(25), 4679-4690, 2006.

IPCC: Intergovernmental Panel on Climate Change, Climate Change 2001: The Scientific Basis: Contribution of Working Group I to the Third Assessment Report of the Intergovernmental Panel on Climate, edited by: Houghton, J. T., Ding, Y., Griggs, D. J., et al., Cambridge Univ. Press, New York, 2001.

Israelevich, P. L., Ganor, E., Levin, Z., and Joseph, J. H.: Annual variations of physical properties of desert dust over Israel, J. Geophys. Res., 108(D13), 4381, doi:10.1029/2002JD003163, 2003.

Kalivitis, N., Gerasopoulos, E., Vrekoussis, M., Kouvarakis, G., Kubilay, N., Hatzianastassiou, N., Vardavas, I., and Mihalopoulos, N.: Dust transport over the Eastern Mediterranean derived from TOMS, AERONET and surface measurements, J. Geophys. Res., 112(D3), 3202, doi:10.1029/2006JD007510, 2007. 
Kerminen, V. and Wexler, A.: Growth behavior of the marine submicron boundary layer aerosol, J. Geophys. Res., 102(D15), 18 813-18 826, 1997.

Lide, D. R.: CRC Handbook of Chemistry and Physics, CRC Press Inc, USA, 1991.

Maenhaut, W., Hillamo, R., Mäkelä, T., Jafferzo, J.-L., Bergin, M. H., and Davidson, C. I.: A new cascade impactor for aerosol sampling with subsequent PIXE analysis, Nucl. Instr. Meth. Phys. Res. B, 109/110 482-487, 1996.

Meng, Z. and Seinfeld, J. H.: On the Source of the Submicrometer Droplet Mode of Urban and Regional Aerosols, Aerosol Sci. Technol., 20, 253-265, 1994.

Mihalopoulos, N., Stephanou, E., Pilitsidis, S., Kanakidou, M., and Bousquet, P.: Atmospheric aerosol composition above the Eastern Mediterranean region, Tellus, 49B, 314-326, 1997.

Putaud, J. P., Raes, F., Van Dingenen, R., Bruggemann, E., Facchini, M.C., Decesari, S., Fuzzi, S., Gehrig, R., H“" uglin, C., Laj, P., Lorbeer, G., Maenhaut, W., Mihalopoulos, N., Muller, K., Querol, X.,Rodriguez, S., Schneider, J., Spindler, G., ten Brink, H., Torseth, K., and Wiedensohler, A.: A European aerosol phenomenology-2: chemical characteristics of particulate matter at kerbside, urban, rural and background sites in Europe, Atmos. Environ., 38, 2579-2595, 2004.

Querol, X., Alastuey, A., Rodriquez, S., Viana, M. M., Artinano, B., Salvador, P., Mantilla, E., Garcia do Santos, S., Patier, R. F., de La Rosa, J., Sanchez de la Campa, A., Menendez, M., and Gil, J.J.: Levels of particulate matter in rural, urban and industrial sites in Spain, Sci. Total Environ., 334-335, 359-376, 2004.

Ravishankara, A. R.: Heterogeneous and Multiphase Chemistry in the Troposphere, Science, 276, 1058-1065, 1997.
Rodriguez, S., Querol, X., Alastuey., A. Kallos, G., and Kakaliagou, O.: Saharan dust contributions to PM10 and TSP levels in Southern and Eastern Spain, Atmos. Environ., 35, 2433-2447, 2001.

Rodriguez, S., Querol, X., Alastuey, A., and Plana, F.: Sources and processes affecting levels and composition of atmospheric aerosol in the western Mediterranean, J. Geophys. Res., 107(D24), 4777, doi:10.1029/2001JD001488, 2002.

Smolik, J., Zdimal, V., Schwartz, J., Lazaridis, M., Harnvanek, V., Eleftheriadis, K., Mihalopoulos, N., Bryant, C., and Colbeck, I.: Size resolved mass concentrations and chemical composition of atmospheric aerosols over the eastern Mediterranean area, Measurements of Particulate Matter, Atmos. Chem. Phys., 3, 22072216, 2003, http://www.atmos-chem-phys.net/3/2207/2003/.

Tegen, I., Heinold, B., Todd, M., Helmert, J., Washington, R., and Dubovik, O.: Modelling soil dust aerosol in the BoDEx depression during the BoDEx campaign, Atmos. Chem. Phys., 6, 43454359, 2006, http://www.atmos-chem-phys.net/6/4345/2006/.

Teinila, K., Kerminen, V.-M., and Hillamo, R.: A study of sizesegregated aerosol chemistry in the Antarctic atmosphere, J. Geophys. Res., 105, 3893-3904, 2000.

Turpin, B. J. and Lim, H.-J.: Species Contributions to PM2.5 Mass Concentrations: Revisiting Common Assumptions for Estimating Organic Mass, Aerosol Sci. Technol., 35, 602-610, 2001.

Viana, M., Querol, X., Alastuey, A., Cuevas, E., and Rodriguez, S.: Influence of African dust on the levels of atmospheric particulates in the Canary Islands air quality network, Atmos. Environ., 36, 5861-5875, 2002.

Wolfenbarger, J. K. and Seinfeld, J .H.: Inversion of aerosol size distribution data, J. Aerosol Sci., 21, 227-247, 1990. 